Original Research Article

\title{
A prospective study of lornoxicam as pre-emptive analgesic in abdominal surgeries in tertiary care hospital in Salem, India
}

\author{
Mohammed Ziauddin Sarkhil ${ }^{1}$, Hemant Kumar Dutt ${ }^{1 *}$, Rajaram S. ${ }^{2}$
}

\begin{abstract}
${ }^{1}$ Department of Pharmacology, Kannur Medical College, Kannur, Kerala, India ${ }^{2}$ Department of Pharmacology, V. M. K. V. Medical College, Salem, Tamil Nadu, India
\end{abstract}

Received: 08 May 2017 Accepted: 02 June 2017

\section{*Correspondence to: \\ Dr. Hemant Kumar Dutt, Email: dr.hemantkdutt@ yahoo.co.in}

Copyright: (C) the author(s), publisher and licensee Medip Academy. This is an openaccess article distributed under the terms of the Creative Commons Attribution NonCommercial License, which permits unrestricted noncommercial use, distribution, and reproduction in any medium, provided the original work is properly cited.

\begin{abstract}
Background: Preemptive analgesia, involves the introduction of an analgesic regimen before the onset of noxious stimuli, with the goal of preventing sensitization of the nervous system to subsequent stimuli that could amplify pain.

Methods: To determine the efficacy and safety of Lornoxicam when administered preemptively by using Wong-Baker FACES Pain Rating scale. The patients undergoing abdominal surgery were randomly categorized into group A and B of 25 each. Group A- Received Lornoxicam 8mg (1ml) one hour before surgery. Group B- Not received any analgesic before surgery. Primary measurement of the efficacy was done by using Wong-Baker Faces Pain Rating Scale at 2, 4, 8, 12 and 24 hour. All parameters were analyzed by using student $t$ test.

Results: Surgeries which were included in the study are hernia repair, open appendectomy, laparoscopic (appendectomy, cholecystectomy). Reduction in pain scores at 12 th hourly and 24 th hourly pain scores $(<0.05)$ was significant. Tramadol usage decreased significantly with laparoscopic surgeries.

Conclusions: In this study we could demonstrate that lornoxicam when used preemptively reduces the pain score slightly and reduces the requirement of post-operative analgesics significantly.
\end{abstract}

Keywords: Lornoxicam, Preemptive analgesia, Wong-Baker faces pain rating scale

\section{INTRODUCTION}

Pain is defined by the International Association for the Study of Pain (IASP) as, "an unpleasant sensory and emotional experience associated with actual or potential tissue damage, or described in terms of such damage". ${ }^{1}$

Proper pain relief which leads to patient wellbeing is the area of focus today. Postoperative pain is a response to tissue trauma after surgery leading to increased production of centrally active PGE2, PGD2, PGI2, and PGF2 which causes central sensitization that leads to hyperalgesia and allodynia due to disinhibition of glycinergic pathways. ${ }^{2}$ COX-2 enzyme leads to central sensitization in early phase of peripheral inflammation subsequently due to upregulation results in prolonged sensitization. ${ }^{3}$ Studies indicate negative outcome leads to decreases in vital capacity and alveolar ventilation, pneumonia, tachycardia, hypertension, myocardial ischemia, myocardial infarction, transition to chronic pain, poor wound healing, and insomnia. ${ }^{4}$ Most common cause of delay in discharge after ambulatory surgery is postoperative pain. In a study that assessed postoperative pain experience and the status of acute pain management the authors concluded that despite an increased focus on pain management programs and the development of new 
standards for pain management, many patients continue to experience intense pain after surgery. ${ }^{4}$

Preemptive analgesiainvolves the introduction of an analgesic regimen before the surgical procedure to prevent peripheral sensitization which is due to stimulation of nociceptors when tissue injury occurs due to the presence of inflammatory mediators like bradykinin, $\mathrm{H}+$, serotonin and ATP, neutrophins (nerve growth factor), LTs, and PGs. ${ }^{5-8}$ Consequently, immediate postoperative pain may be reduced and the development of chronic pain may be prevented. Experimental evidence suggest it is preferable, to prevent or pre-empt' the neurophysiological and biochemical consequences of anxious input to the CNS rather than to begin treatment when these consequences are already established. Accordingly, prevention of postoperative pain may be more effective than treatment. ${ }^{8}$ Surgery offers the most promising setting for pre-emptive analgesia because the timing of noxious stimuli is known. Hence adequate doses of analgesic can be administered before surgery leadingto prevention of post-operative pain from getting established which is difficult to treat. ${ }^{7}$

NSAIDs are a chemically heterogeneous group of compounds, which nevertheless share certain therapeutic actions and adverse effects. The principal therapeutic effects of NSAIDs derive from their ability to inhibit PG production. The first enzyme in the $\mathrm{PG}$ synthetic pathway is COX, This enzyme converts AA to the unstable intermediates $\mathrm{PGG} 2$ and $\mathrm{PGH} 2$ and leads to the production of the prostanoids, TxA2, and PGs. ${ }^{9}$

Peripheral pain stimulus leads to increased production of PGs (PGE2) which in turn lead to increase terminal membrane excitability of ion channels on nociceptors. This peripheral sensitization reversal is the basis of action of NSAID. Central and spinal action of NSAID is due to presence of COX 1 and COX2enzymes. ${ }^{10}$

Lornoxicam is a non-steroidal anti-inflammatory drug (NSAID) of the oxicam class with analgesic (pain relieving), anti-inflammatory and antipyretic (fever reducing) properties. It is available in oral and parenteral formulations. Lornoxicam is unique among the enolic acid derivatives in that it has a rapid onset of action and a relatively short $t_{1 / 2}$ (3-5 hours). ${ }^{11}$

Lornoxicam inhibits prostaglandin biosynthesis by acting on both COX-1 and COX-2 enzymes with ratio of $1: 1 .^{12}$ Efficacy in treatment of postoperative pain when given by intravenous route is comparable to morphine $(20 \mathrm{mg})$, pethidine $(50 \mathrm{mg})$ and tramadol $(50 \mathrm{mg}) .^{13}$ Orally when administered absorption is complete with no first pass metabolism achieving plasma concentration within 1 to 2 hours. Enzyme CYP2C9 is responsible forbiotransformation. Major route of elimination is hepatic $2 / 3$ and remaining $1 / 3$ via renal. ${ }^{11}$ Lornoxicam oral dose is 8 to $16 \mathrm{mg}$ daily for the treatment of pain. Similar doses may be given by intravenous or intramuscular injection, although in rare cases the maximum initial daily dose may be increased to $24 \mathrm{mg} .{ }^{14}$

Lornoxicam has a tolerability profile characteristic of NSAIDs, most prominent side effects seen are due to gastrointestinal disturbances (pain, dyspepsia, nausea, vomiting). Caution is recommended in patients with impaired renal function (although dosage adjustment does not appear to be necessary). In comparative clinical trials, the tolerability of oral lornoxicam appeared to be similar to that of diclofenac and better than that of indomethacin in patients with arthritic conditions or chronic low back pain. As would be expected, parenterally administered lornoxicam tended to be better tolerated than parenteral opioid analgesics in patients with postoperative pain. ${ }^{15}$

The clinical trials published so far, mostly comparative, clearly document the efficacy of lornoxicam as a potent analgesic with anti-inflammatory properties in a range of painful and/or inflammatory conditions, including postoperative pain and rheumatoid arthritis. ${ }^{15}$

Hence, this study was aimed at determining the efficacy and safety of lornoxicam as pre-emptive analgesics in patients who have undergone elective abdominal surgeries.

\section{METHODS}

\section{Study population}

Patients undergoing Abdominal surgery in Vinayaka Mission's Kirupananda Variyar medical college were enrolled. The study was done from Nov 2012 to Aug. 2013.

\section{Inclusion criteria and exclusion criteria}

The study included patients in the age group of 18 to 50 years and with ASA (American Society of Anesthesiologists) grade 1 and 2 who are undergoing abdominal surgery. The patients who were taking antiplatelet drugs, allergic to NSAIDs and who had a history of alcohol abuse and gastric ulcer were excluded. Pregnant women, children and those with history of hepatic, renal and cardiac impairment were also excluded.

\section{Study drug}

Lornoxicam (LORSAID by Abbott India Ltd.) $8 \mathrm{mg}$ injection constituted in $2 \mathrm{ml}$ of sterile distilled water and administered one hour before surgery.

\section{Study procedure}

Informed consent was taken from the participants. All the details of the nature and purpose of the study were described in the local language to the patient. An individual who voluntarily gave the informed consent was enrolled in the study. 
The routine pre-anesthetic examinations and investigations of all the patients were done on the previous day of the surgery. The patients received Tab. Alprazolam $0.25 \mathrm{mg}$ and Tab. Ranitidine $150 \mathrm{mg}$ at night. The 50 patients were randomly allocated the groups $(n=25)$. The odd numbered were assigned test group and even numbered the control group.

- Group A: Receiving Lornoxicam 8mg (2ml) i.v one hour before surgery

- Group B: Not receiving any analgesic before surgery.

The patients were administered a rescue medication, injection Tramadol $2 \mathrm{mg} / \mathrm{kg}$ body weight post-operatively, when the Wong-Baker FACES Pain Rating Scale score was more than four.

\section{Efficacy assessment}

Pain is often regarded as the fifth vital sign in regard to healthcare because it is accepted now in healthcare that pain, like other vital signs, is an objective sensation rather than subjective. ${ }^{16}$ There are many pain measurement scales like Dallas Pain Questionnaire, Faces Pain Scale Revised (FPS-R), Wong-Baker FACES Pain Rating Scale, and Visual analog scale (VAS). ${ }^{17-20}$

Visual analog scale (VAS): is a measurement instrument that tries to measure a characteristic or attitude that is believed to range across a continuum of values and cannot easily be directly measured. The VAS is a subjective measure of pain it consists of a $10 \mathrm{~cm}$ line with two end-points representing 'no pain' and 'worst pain imaginable'. ${ }^{20}$

Wong-Baker FACES Pain Rating Scale: This scale can be used with young children (sometimes as young as 3 years of age). It also works well for many older children and adults as well as for those who speak a different language. Explain that each face represents a person who may have no pain, some pain, or as much pain as imaginable. Point to the appropriate face and say:

- (0) This face is happy and does not hurt at all.

- (2) This face hurts just a little bit.

- (4) This face hurts a little more.

- (6) This face hurts even more.

- (8) This face hurts a whole lot.

- (10) This face hurts as much as you can imagine, but you don't have to be crying to feel this Bad.

Ask the patient to choose the face that best matches how she or he feels or how much they hurt (Figure 1). ${ }^{19}$

The primary measurement of the efficacy was the pain intensity score which was measured on Wong-Baker FACES Pain Rating Scale at $2^{\text {nd }}, 4^{\text {th }}, 8^{\text {th }}, 12^{\text {th }}$ and $24^{\text {th }}$ hours. The patients were first trained before the surgery about the Wong Baker Faces Pain Rating Scale. The first reading was taken at 2 hours after surgery, then at 4, 8, 12 and 24 hours. The total Wong-Baker FACES Pain Rating Scale at the end of 24 hours was assessed to compare the analgesic efficacy between the two groups. The analgesic duration, which is the duration of the analgesia between the time of the end of the Surgery and the time of the first rescue dose of analgesia was noted. In addition, the total amount of the rescue medication which was given was also noted.

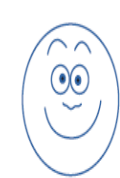

0
No
Hurt
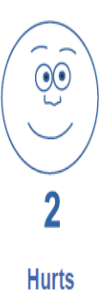

Little Bit
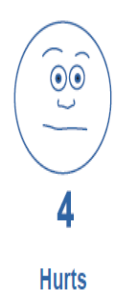

Little More
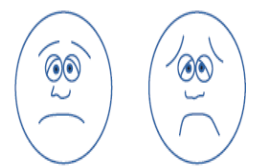

6

Hurts

Even More

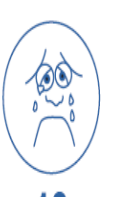

10

Hurts Worst

\section{Figure 1: Wong baker faces pain rating scale.}

\section{Statistical analysis}

Statistical analysis was done by using spss16 software. All parameters were analyzed by using student $\mathrm{t}$ test. Parameters such as age and sex were analyzed by chi square test. $\mathrm{P}<0.05$ was considered significant in the study.

\section{RESULTS}

In the study, the total of 50 patients who participated underwent abdominal surgeries which included hernia repair (umbilical, paraumbilical, incisional, epigastric), open appendicectomy, laproscopic (appendicectomy, cholecystectomy, tubal recannulation). Out of the 50 patients, 25 patients received Lornoxicam $8 \mathrm{mg}$ i.v. constituted test group or group 1 and 25 patients were taken as control group or group 2 . The gender distribution has been shown (Figure 2).

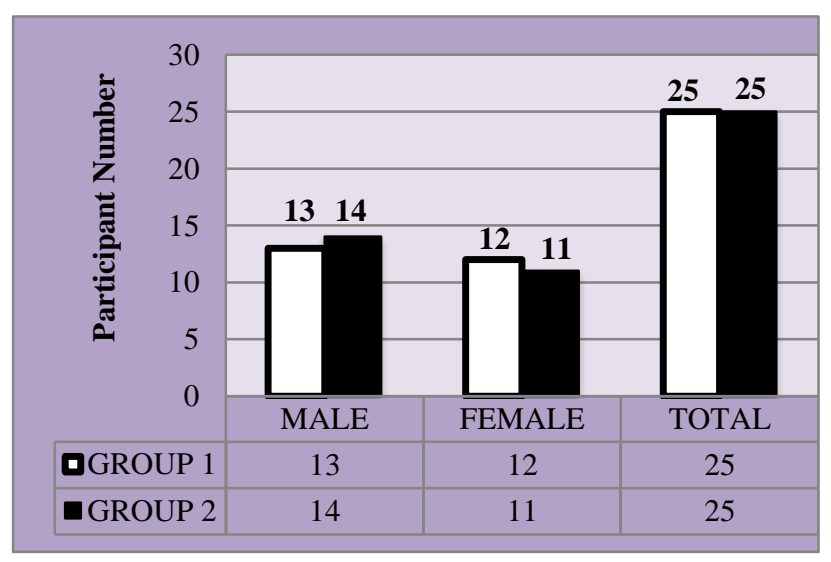

Figure 2: Gender distribution.

The basic parameters like mean age, mean gender, mean weight, mean duration of surgery (Table 1) and when 
these parameters compared between the two groups were not found statistically significant.

Table 1: Mean \pm SEM values of parameters.

\begin{tabular}{|lll|}
\hline Parameters & Group 1 & Group 2 \\
\hline Age (in years) & $34.68 \pm 11.785$ & $35.96 \pm 10.880$ \\
\hline Weight (in Kg) & $58.20 \pm 10.484$ & $56.12 \pm 6.990$ \\
\hline $\begin{array}{l}\text { Duration of surgery } \\
\text { (in minutes) }\end{array}$ & $89.40 \pm 38.92$ & $98.48 \pm 35.18$ \\
\hline $\begin{array}{l}\text { Time for first } \\
\text { appearance of pain } \\
\text { after pre emptive } \\
\text { analgesic (in minutes) }\end{array}$ & $87.92 \pm 80.363$ & $60.40 \pm 55.338$ \\
\hline $\begin{array}{l}\text { Total dose of } \\
\text { Tramadol after } \\
\text { surgery (in milligram) }\end{array}$ & $150 *$ & 200 \\
\hline *p< 0.05 & & \\
\hline
\end{tabular}

To test the efficacy of Lornoxicam, the pain scores was done by recording the pain intensity score by using Wong-Baker FACES Pain Rating Scale (Figure 1) at 2, 4, 8,12 and 24 hours subsequently. The pain scores are shown (Figure 3) between the two groups, even though pain score results from $1^{\text {st }}$ pain score to $8^{\text {th }}$ hourly pain score have reduced in Group1 when we compare with Group2 the reduction is not statistically significant. But the $12^{\text {th }}$ hourly and $24^{\text {th }}$ hourly pain scores between the two groups the reduction in the group 1 is statistically significant $(<0.05)$. The reduction in pain scores were predominant with laparoscopic operations where as with other Surgeries there was a slight but not much difference compared with the pain scores of the control group.

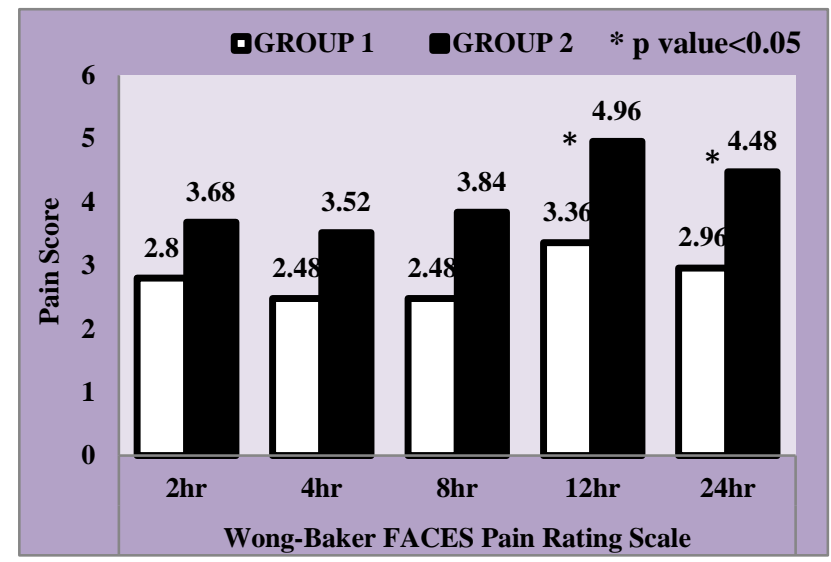

Figure 3: Wong-Baker FACES pain rating scale.

Reduction in pain scores when two groups were compared was statistically significant $(<0.05)$. The reduction in pain scores were predominant with laparoscopic operations where as with other Surgeries there was a slight but not much difference compared with the pain scores of the control group.

The time required for first use of analgesic by the patient after surgery is shown in Table 1 . Two patients in group 2 demanded analgesic before one hour. Though the difference can be seen in the duration between the two groups but as the sample size is very small the difference is not statistically significant.

The total usage of Tramadol (in mg) in 24 hours (Table 1). The difference in the mean values between the two groups is statistically significant. In this study the usage of tramadol was different only in the laparoscopic surgeries as 3 patients from the group 1 did not require any tramadol during 24 hours after the operation. Remaining 7 laparoscopic surgery patients of group 1 required less doses of tramadol. All 9 laparoscopic patients in group 2 required much more dose. Where as in other surgeries like hernia or acute appendicectomy the usage of tramadol was similar to the group 2 patients.

\section{DISCUSSION}

Earlier studies showed different timings for measuring the pain score; Inan $\mathrm{N}$ et al, measured the pain score at $1^{\text {st }}, 2^{\text {nd }}, 3^{\text {rd }}, 4^{\text {th }}, 6^{\text {th }}, 8^{\text {th }}, 12^{\text {th }}, 18^{\text {th }}, 24^{\text {th }}, 36^{\text {th }}, 48^{\text {th }}$, Kirdemir et al, at $0,1^{\text {st }}, 2^{\text {nd }}, 3^{\text {rd }}, 6^{\text {th }}, 10^{\text {th }}$, and $24^{\text {th }}$ hours, Wanghui et al, at 2, 4, 8, 12, 24, 48h and Girish Babu Narasimha Murthy et al, at 2, 4, 8, 12 and 24 hours. $^{21-24}$ The later pain score measuring time intervals was used in our study.

All the above studies listed have used VAS (Visual analogue score) score and 5-VRS (5-Point verbal rating scale). In our study the pain score was recorded using Wong-Baker FACES Pain Rating Scale as it was convenient to record the pain scores in the less literate patient population and to eliminate any bias by the investigator.

Inan $\mathrm{N}$ et al, demonostrated the use of lornoxicam in doses of $16 \mathrm{mg}$ before surgery and $8 \mathrm{mg}$ in first $24 \mathrm{hr}$ (12,24 two doses) postoperatively significantly decreased the usage of morphine when compared to patients who didn't receive lornoxicam pre or post operatively in patients undergoing total hip replacement. ${ }^{21}$

Kirdemir et al, compared efficacy of lornoxicam and tramadol as preemptive analgesic for postoperative pain in patients undergoing laparoscopic cholecystectomy it was seentotal drug consumption was decreased and significant pain relieve was also in both groups. Pain relief was higher with lornoxicam group. ${ }^{22}$

Wanghui et al, in a study used lornoxicam as preemptive analgesic in senile patients undergoing femoral intertrochanteric fracture demonstrated significant lowered VAS scores. Analgesic satisfaction score and sleep satistisfaction score were significantly higher than the control group. ${ }^{23}$

Girish babu narasimha murthy et al, compared ketorolac with lornoxicam as pre emptive analgesic in patients undergoing elective abdominal surgeries. Pain scores 
when compared to placebo group are significantly lower in lornoxicam group $(p=0.0001)$. The time for the first analgesic requirement was longer in lornoxicam $302.75 \pm 92.57 \mathrm{mins}$ and the ketorolac groups $291.25 \pm 100.34 \mathrm{mins}$ as compared to that in placebo group $107.50 \pm 50.71 \mathrm{mins}(\mathrm{p}=0.0001)$. Significant difference was seen in the analgesic consumption between the group (ketorolac $47 \%$ and lornoxicam 54\% group) compared to that in placebo group $(\mathrm{p}=0.0001){ }^{24}$

Karaman Y and others assessed the effect of lornoxicam as pre emptive analgesic in patients undergoing major abdominal surgery concluded that lornoxicam administered pre emptively results in lesser usage of tramadol in this group of patients. ${ }^{25}$

Petrova VV et al, studied lornoxicam as an agent for the prevention and treatment of postoperative pain after extensive cancer surgery. The study proved that lornoxicam used in therapeutic doses show a $50 \%$ reduction (versus $30 \%$ when ketorolac or ketoprofen is used) for the need of potent Opiod buprenorphine after extensive operations of cancer. ${ }^{26}$

Cervik E et al, using VAS pain scores to study efficacy of IV tenoxicam, lornoxicam, dexketoprofen and tramadol in patients suffering from renal colic concluded all drugs used in study are effective, more reduction of pain scores is seen with lornoxicam group. ${ }^{27}$

Inanoglu K and colleagues concluded that IV lornoxicam given pre emptively had a better pain relieving effect for varicocectomy than when administered post operatively. ${ }^{28}$

Farnad Imani et al studied the efficacy of morphine and lornoxicam following use of patient control intravenous analgesia for pain after laparoscopic gastric bypass surgery. The results suggest the lornoxicam is as efficacious as morphine in management of postoperative pain in patients undergoing laproscopic surgery by using PCIA. In addition lornoxicam has less side effects such as sedation nausea and vomiting. ${ }^{29}$

Tugba Karaman et al, used both paracetamol and lornoxicam as preemptive analgesic concluded that total usage of tramadol was reduced ( $p$ <0.001) when compared to control group but inter drug variation was not significant. ${ }^{30}$

Arslan $\mathrm{M}$ et al, assessed the analgesic effects in patients undergoing thyroidectomy by using IV Paracetamol and lornoxicam in postoperatively pain. They could demonstrate opiod requirement is reduced postoperatively, pain scores got reduced, and time for first following IV paracetamol and IV lornoxicam administration. There was a significant reduction in the incidence of nausea and vomiting and also significantly prolonged the time for the first rescue analgesic requirement. ${ }^{31}$
All the mentioned studies in the article demonstrate the efficacy of lornoxicam as a pre emptive analgesic agent in a variety of surgical procedures. In our study we tried to analyze the efficacy of lornoxicam in the abdominal surgery patients when used as a preemptive analgesic agent for the reduction of post-operative pain and for subsequent reduction in the requirement of Opioid analgesics. It was demonstrated lornoxicam preemptively reduces pain scores slightly and reduces requirement of post-operative analgesics significantly.

\section{CONCLUSION}

The post-operative period is an important part of surgical experience and affects recovery. Many advances have been made in the field of pain management with the advent of newer analgesic agents and techniques. However patients continue to experience moderate to severe pain post operatively. The concept of pre emptive analgesia suggests that the best post-operative pain management begins pre- operatively. The present study states that pre emptive administration of lornoxicam in patients undergoing abdominal surgery is associated with lower pain intensity and subsequent lower analgesic requirement in the postoperative period when compared to the control group. The study reaffirms the findings of the previous studies mentioned in discussion and shows that lornoxicam can be used as a suitable alternative to the other NSAIDS because of its better GI tolerability and shorter duration of action.

Funding: No funding sources

Conflict of interest: None declared

Ethical approval: The study was approved by the Institutional Human Ethical Committee

\section{REFERENCES}

1. Moayedi M, Davis KD. Theories of pain: from specificity to gate control. J of Neu. 2013;109(1):512.

2. Reinold H, Ahmadi S, Depner UB, Layh B, Heindl C, Hamza M, et al. Spinal inflammatory hyperalgesia is mediated by prostaglandin E receptors of the EP2 subtype. J Clin Invest. 2005 Mar;115(3):673-9.

3. Samad TA, Moore KA, Sapirstein A, Billet S, Allchorne A, Poole $\mathrm{S}$ et al. Interleukin-1betamediated induction of Cox-2 in the CNS contributes to inflammatory pain hypersensitivity. Nature. 2001;410(6827):471-5.

4. Vadivelu N, Mitra S, Narayan D. Recent Advances in Postoperative Pain Management. Yale J Biol Med. 2010;83(1):11-25.

5. Lopshire JC, Nicol GD. The cAMP transduction cascade mediates the prostaglandin E2 enhancement of the capsaicin-elicited current in rat sensory neurons: Whole-cell and single-channel studies. J Neurosc. 1998;18:6081-92.

6. Pulichino AM, Rowland S, Wu T, Clark P, Xu D, Mathieu MC, et al Prostacyclin antagonism reduces 
pain and inflammation in rodent models of hyperalgesia and chronic arthritis. J Pharmacol Exp Ther. 2006;319(3):1043-50.

7. Gottschalk A, Smith DS. New Concepts in Acute Pain Therapy: Preemptive Analgesia. Am Fam Physician. 2001;63(10):1979-85.

8. Dahl JB, Møiniche S. Pre-emptive analgesia. Br Med Bull. 2004;71:13-27.

9. Brunton LL. Goodman \& Gilman's The Pharmacological Basis of Therapeutics $12^{\text {th }}$ Ed. Chapter 34. Anti-inflammatory, antipyretic, and analgesic agents; 2011:959-975.

10. Vanegas H, Schaible HG. Prostaglandins and cyclooxygenases in the spinal cord. Prog Neurobiol. 2001;64:327-63.

11. Kadoli PS, Desai SR, Payghan SA, D’Souza JI. Study of Binding Efficiency of Tapioca Starch using Iornoxicam as a Model Drug. International Journal of Pharmaceutical \& Biological Archives 2012;3(1):223-7.

12. Bansal T, Thakur A, Hooda S. Comparison of Efficacy of Lornoxicam and Diclofenac for Postoperative Pain Relief in Patients Undergoing Abdominal Hysterectomy. Int J Pharm Pharm Sci. 2011;3(4):285-9.

13. Temeltaş G, Asan C, Müezzinoğlu T, Büyüksu C. An Evaluation of the Efficacy of Lornoxicam in Acute Renal Colic Treatment. İnönü Üniversitesi Tıp Fakültesi Dergisi. 2008;15(1):1-3.

14. Sweetman SC. Martindale The Complete Drug Reference, pharmaceutical press $26^{\text {th }}$ Edition; 2009:77-78.

15. Balfour JA, Fitton A, Barradell LB. Lornoxicam. Drugs. 1996 Apr 1;51(4):639-57.

16. Morone NE, Weiner DK. Pain as the 5th Vital Sign: Exposing the vital need for pain education. Clin Ther. 2013 Nov;35(11):1728-32.

17. Lawlis GF, Cuencas R, Selby D, McCoy CE. The development of the Dallas Pain Questionnaire. An assessment of the impact of spinal pain on behavior Spine.1989;14(5):511-6.

18. Hicks CL, von Baeyer CL, Spafford P, van Korlaar I, Goodenough B. The Faces Pain Scale - Revised: Toward a common metric in pediatric pain measurement. Pain. 2001;93:173-83.

19. Wong DL, Hockenberry-Eaton M, Wilson D, Winkelstein ML, Schwartz P. Wong's Essentials of Pediatric Nursing, 6/e, St. Louis; 2001:1301.

20. Hawker GA, Mian S, Kendzerska T, French M. Measures of adult pain: Visual Analog Scale for Pain (VAS Pain), Numeric Rating Scale for Pain (NRS Pain), McGill Pain Questionnaire (MPQ), ShortForm McGill Pain Questionnaire (SF-MPQ), Chronic Pain Grade Scale (CPGS), Short Form-36 Bodily Pain Scale (SF-36 BPS), and Measure of Intermittent and Constant Osteoarthritis Pain (ICOAP). Arthritis Care \& Research. 2011;63(S11):S240-52.

21. Inan N, Özcan N, Takmaz SA, Özcan A, Erdogan I, Baltaci B. Efficacy of lornoxicam in postoperative analgesia after total knee replacement surgery. Experimental and Clinical studies. Agri. 2007;19:2.

22. Kırdemir P, Marşan A. Comparing efficacy of pre emptively used lornoxicam and tramadol for postoperative pain in patients underwent laparoscopic cholecystectomy. Journal of clinical and experimental investigations. 2010;1(1):1-6.

23. Hui W, Lin G. Clinical observation of pre emptive analgesia efficacy of administrate ring lornoxicam on senile patients undergoing femoral intertrochanteric fracture. Modern Medicine \& Health. 2010-12.

24. Murthy GBN, Bengalorkar GM, Madhusudhana R. Comparative Study of Ketorolac with Lornoxicam as Pre-emptive Analgesics in Patients Who were Undergoing Elective Abdominal Surgery under General Anaesthesia. Journal of Clinical and Diagnostic Research. 2012;S1,6(3):418-22.

25. Karaman Y, Kebapci E, Gurkan A. The preemptive analgesic effect of lornoxicam in patients undergoing major abdominal surgery: A randomised controlled study.International Journal of Surgery. 2008;6(3):193-6.

26. Petrova VV, Osipova NA, Beresnev VA, Dolgopolova TV, Biriukov VI, Torchinskaia EV, et al. Lornoxicam (xefocam) as an agent for the prevention and treatment of postoperative pain among other nonsteroidal anti-inflammatory drugs. Anesteziol Reanimatol. 2005;(5):39-43.

27. Guzel AL, Kuyumcuoglu U, Celik Y. Compative efficacy of lornoxicam in pain relief in endometrial sampling. Journal of experimental therapeutics \& oncology. 2012;9(4):317-20.

28. Inanoglu K, Gorur S, Akkurt CO, Guven OE, Kararmaz A. The analgesic efficacy of preoperative versus postoperative lornoxicam in varicocele repair. J of Clin Ane. 2007;19(8):587-90.

29. Imani F, Alimian M, Radmehr M, Deljou A, Mirabi N. Comparison of Morphine and Lornoxicam following PCIA pain after laproscopic gastric bypass surgery Journal of Anesthesiology and Pain. 2010;1(1):63-70.

30. Karaman T, Kuzucuoglu T, Arslan G, Karaman S, Hatun M. Comparison of the Analgesic Effects of Preemptive Lornoxicam and Paracetamol after Laparoscopic Cholecystectomy. Int $\mathbf{J}$ Anesthetic Anesthesiol. 2016;3:047.

31. Arslan M, Ciçek R, Celep B, Yılmaz H, Kalender UH. Comparison of the analgesic effects of intravenous paracetamol and lornoxicam in postoperative pain following thyroidectomies. Agri. 2011;23(4):160-6.

Cite this article as: Sarkhil MZ, Dutt HK, Rajaram $\mathrm{S}$. A prospective study of lornoxicam as pre-emptive analgesic in abdominal surgeries in tertiary care hospital in Salem, India. Int J Basic Clin Pharmacol 2017;6: 1778-83. 